\title{
Sinusite maxillap
}

A anesthesia local no seu tratamento radical Por Pofyguar Medeiros, $3 .^{\circ}$ annista.

Frequentes têm sido os casos desta affecção tratádos na clinica de oto-rhino-laryngologia da Santa Casa.

O director da clinica, professor Henrique Lindemberg, chamou nossa attenção para o processo de anesthesia adoptado quando se pratica o seu tratamento radical.

A simplicidade do methodo foi inspiração para que escrevessemos este pequeno artigo, que, embora só a feitura tenha de original, anima-se de dupla pretenção: diffundir c methodo e proporcionar aos nossos collegas algumas notas sobre o que de mais importante haja no assumpto referente á sinusite maxillar.

No tratamento radical desta molestia, os anesthesicos locaes têm dado resultados de tal forma satisfactorios, que a chloroformisação não tem mais razões a seu favor: á sua efficacia, igual á do chloroformio, junta-se, na anesthesia local, um factor de grande valia — a simplicidade de applicação.

Lançada a these que pretendemos defender tanto escudados na benevolencia alheia como nas nossas proprias forças; faremos a seguir algumas considerações sobre a molestia de que nos occupamos.

De todas as inflammações das cavidades accessorias do nariz, a do seio maxillar é a mais frequente.

Em primeira analyse consiste a sinusite em uma inflammação da mucosa sinusal, havendo na cavidade uma collecção de pús; é esta a manifestação rigorosa e constante da sinusite.

Assim nos exprimimos porque nesta mesma cavidade, póde haver em algum tempo, granulações consequentes á destruição da mucosa por parte do pús; outras vezes, porque a molestia retroceda logo no inicio, póde não attingir este gráo avançado e a sinusite fica sendo apenas um processso purulento-inflammatorio do seio.

Dahi a divisão das sinusites em agudas e chronicas. 
Uma sinusite é aguda, quando a mucosa sinusal se apresenta sómente inflammada, quando no antro ha pús sem haver ahi mesmo, nenhum polypo; a sinusite neste estado tem o nome de empyema.

O empyema, trez, seis até doze mezes depois de sua irrupção, passa a ser sinusite chronica ou verdadeira. A este tempo a mucosa perdeu de todo a integridade histologica: resolveu-se em granulações ou polypos que mergulham no pús da cavidade.

O producto de secreção da mucosa assim degradada, é degenerado, apresenta-se alterado, com um caracter francarronte purulento.

Por isto é que Lermoyez dizia ser o seio, na sinusite chronica uma fabrica de pús, emquanto que no empyema não era mais do que um entreposto, um deposito.

Este auctor considera além do empyema e da sinusite chronica, a sinusite agudda; esta, seria a propagação ao seio maxillar, de uma rhinite aguda.

Consideremos entretanto, deixando de lado o empyema, apenas as duas formas de sinusité chronica e aguda.

Sob o ponto de vista etiologico, esta ultima póde ter ou uma origem infecciosa ou uma origem traumatica ou, o que é mais commum, uma origem dentogena.

A sinusite chronica póde ser produzida, sem que haja primariamente uma sinusite aguda, pela syphilis ou pela tuberculose: quando ella seja secundaria, isto é, quando a sinusite chronica seja uma phase adeantada da sinusite aguda, terá, é claro, os mesmos pontos de partida desta ou molestia infectuosa ou traumatismo ou affecção dentaria.

Examinemos estes pontos.

A fractura do maxillar ao nivel do seio, é algumas vezes causa de uma sinusite, como tambem o é a penetração de um corpo extranho no antro.

Estas duas causas podem estar reunidas dando-se o caso de haver uma fractura do maxillar e um fragmento deste osso penetrar no seio.

Mas, o corpo extranho causador da sinusite, penetra quasi sempre ou pelo orificio natural ou pelo ostio acces- 
sorio o que constitue caso raro, ou por um orificio que exista accidentalmente e que communique o antro a um alveolo dentario.

Aqui o corpo extranho é representado mais commumente por uma particula alimentar: para se fugir a este perigo é que se abandonou o antigo processo de trepanação do seio maxillar pelo alveolo de um dente.

As molestias infectuosas são mais vezes qué os traumatismos, causas de sinusite. Nesta classe, occupa lugar predominante, a grippe: ella fornece $800 \mid 0$ das sinusites produzidas por molestias preexistentes.

Entre as outras molestias relacionadas com a sinusite maxillar, têm/destaque, a sinusite frontal, a variola, a pneumonia, a escarlatina, ete.

A sinusite constatada no curso de um coryza agudo ou durante uma rhinite tambem aguda, é banal, desapparece com estas causas ou pouco tempo depois dellas.

Parece que a causa mais frequente da sinusite maxillar é representada pelas infecções dentarias, focalisadas ou no proprio dente ou nos seus annexos.

Com effeito, a sinusite maxillar póde ser producto de uma carie dentaria acompanhada de uma infecção: por outro lado, a pericimentite, inflammação do ligamento alveolo-dentario, muito embora não haja carie no dente em que ella se manifesta, póde provocar uma sinusite, facto que se explica pelas causas que determinam esta pericimentite e pelos effeitos decorridos della.

A pericimentite é consequencia de lesões da polpa e da infecção dos canaes radiculares dos dentes: tem como epilogo, seja ella aguda ou chronica, a formação de um abcesso que na maior parte das vezes se vae abrir no seio maxillar.

Conclue-se pois, que ha relação de causa entre a sinusite maxillar e as infecções dentarias, podendo-se especialisar esta relação para os canaes radiculares, dizendo-se com Lermoyez que a infecção dentaria attinge o antro de Highmore, tendo por via unica os canaes radiculares.

As infecções dentarias serão causa tanto mais efficiente, quanto mais delgado fôr o plano osseo que isole da cavi- 


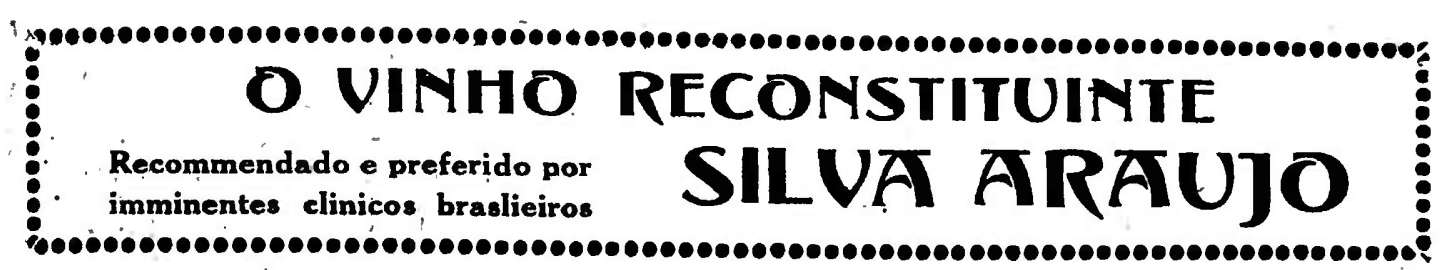

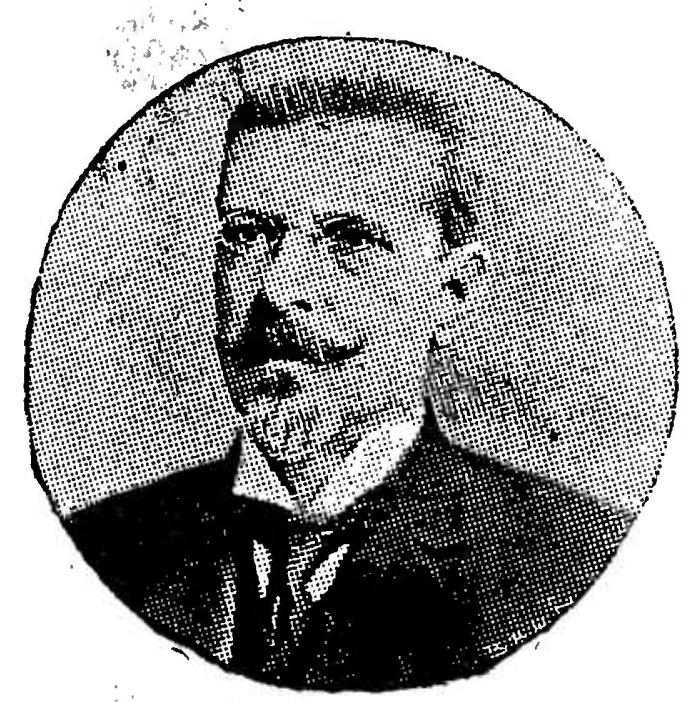

"de preparados analogos, nenhum a mei ver, lhe e superior e poucos o igualam, sejam nacionaes ou extrangeiros; a todos, porém, o prefiro sem hesitação, pela efficacia e pelo meticuloso cuidado de seu preparo a par do sabor agradavel ao paladar de todos os doentes e convalescentes." Prof. ROCHA FARIA.

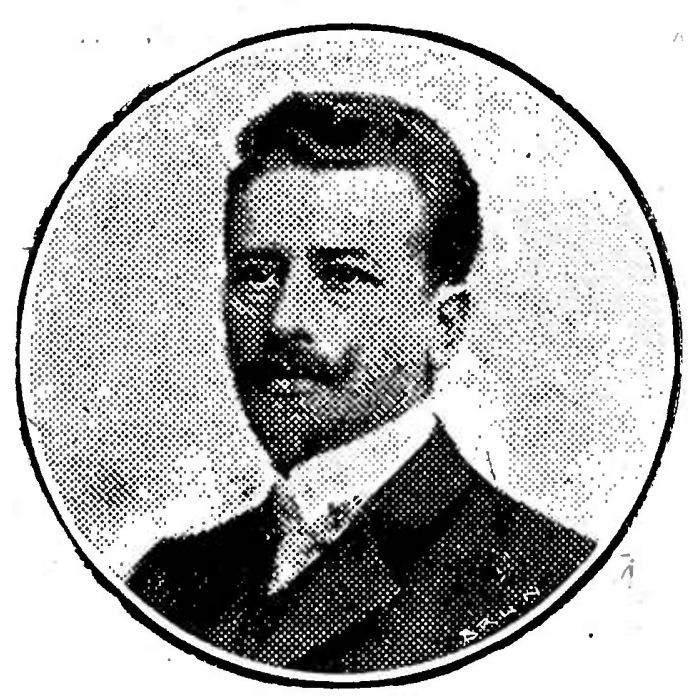

"6 este um preparado que merece a minha inteira confiança".

Prof. MIGUEL PEREIRA.

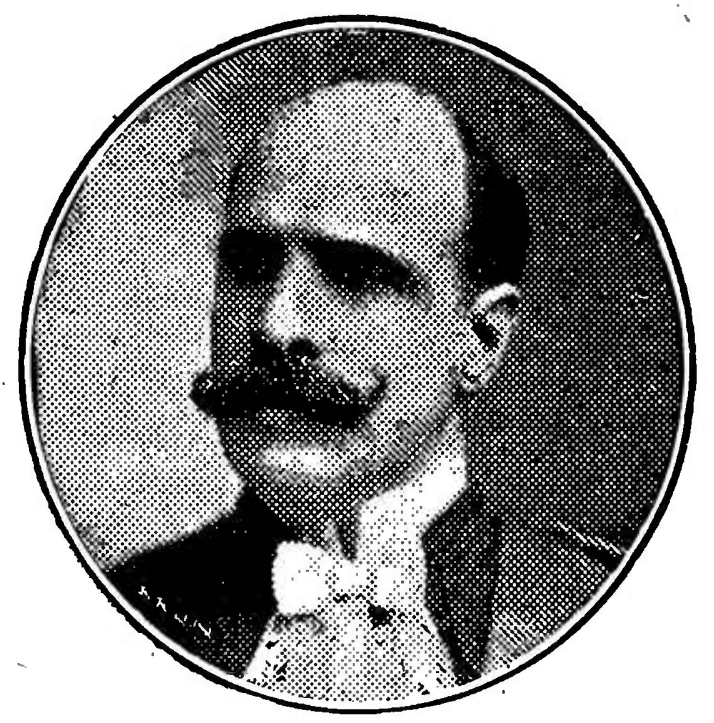

"excellente preparado que é empregado com a maxima confiança $\mathrm{e}$ sempre com efficacia nos casos adequados." .

Prof. MIGUEL OOUTO.

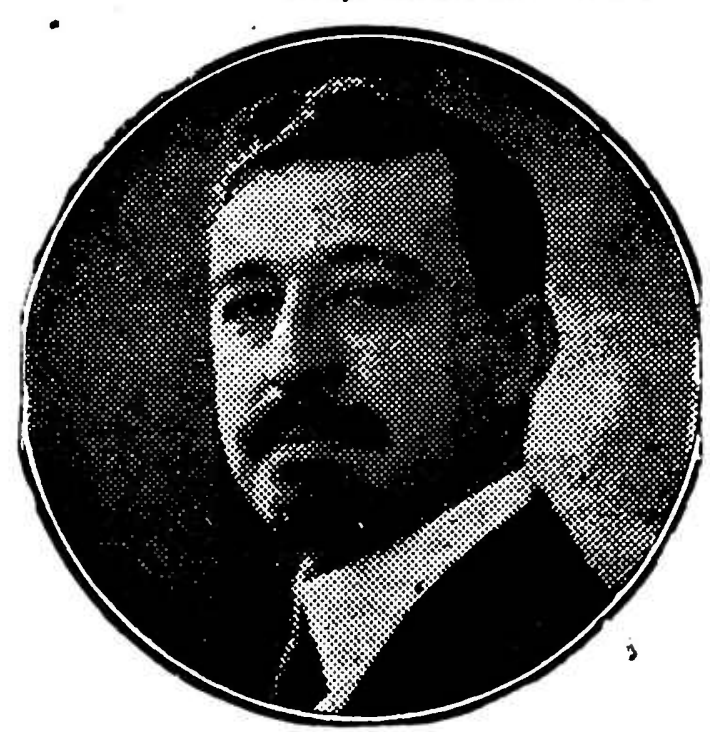

“...excellente tonico nervino e hematogenico applicavel a todos os casos de debilidade geral e de qualquer molestia infectuosa." Prof. A. AUSTREGESILO. 


\section{Instituto Sieroterapico Milanese}

Os preparados do "Instituto Sieroterapico Milanese", para uro hjpedermico, contêm o "RIVELATORE GOSIO", que demonstra a sua esterillăçăo. Tratando-se, pois, de preparaçoses orgamicas, facilmente alteravein, a esterilisação visivel destes preparados é da maxima importancia.

Todos os productos do mesmo "Instituto" que sè vendem no. Bram têm uma preparaç่̃o e cónfeccño especial para a travessia do equador, e de conformidade om as exigencias do clima, temperatura e condiçóes ear peciaes do. paiz. Cada frasco deve trazer o rotulo com as geguintes palavras: "Preparagão especial para o Brasil. Exclusivos concessionarion pars a introduceño e venda: - DE MATTIA \& CO. - S. Paulo.

0 publico ñ̃o deve portanto, acceitar como legitimos, os productos que não tragam os dineres supracitados, porque podem ter aoffrido algunas alteraçös.

Adrenalima - Principio vaso-constrictor da glaudula supra-rhenalAdstringente, ischemizante, hemostatico potentissimo.

Usa-se.nas hemorrhagias de qualiquer esperie Soluçăo 1:100 em vidro de 10.0 e caixa de 8 ampôllas.

Antitiroidina - Do serum dos animaes esthyroidados - Cura a doenca de BASEDOW, diminué a glycosuria nos diabeticos. A antitiroidina extrahida do serum é talvez mai sadtiva que a extrahida do lieite. Em vidro de 50 pastilihais.

Piara tomar 6-i10 pastilhas por dia, $2-4$ de cada vez.

Atussin - (Extracto de glandula supra-rhenal) associado a substancias sedatias segundo coniselho do doutor ViALSASSORI-PERONI. Cura rapildamente a colqueluche, previne as complicações broneho-pulmonares.

Em vidro de 30,0. Para tomar 5-10 gottas 3-4 vezes por dia.

Caseasi - (Fermento para a digestão do leite). Peptoniza 'o lieite, impedindo a coagulação, tornando-o perfeitamente digerivel. Basta uma pastiliha dissolvida num pouco de leite antes de bebel-o. Vidro de 50 pastilhas.

Endobilina - Lilpoide biliares em solução oleosa. Applica-se na cura da tuberculose, especialmente indicada na enterite tuberculosa. Fm caixa de 8 ampôllas.

Endocerebrima - Elfficaz nas formas de neurasthenia, epilepsia, anomalias pisychicas e no alcoolismo chronico, insomnia, tremor. Vidro de 50 pastilhas

Endolpofisina - (Principio activo da glandula hypóphyse in toto). Indicado contra as anomalias do desenivolvimento e nos casos nos quaes é deficiente a reacção da nutrição do tecido osseo Em solucắo pastilhas e ampôllass. Para tomar.44-18 pastilhas ou 10'-15 gottas por dia, em 3 vezes, antes das refeições.

Endopituitrima - Extracto do lobo-posterior da ihypoiphyse. Determina o áugmento da pressão sanguinea e é um poderoso tónico do 'musculo utero, no qual provoca as contraccões. Util, portanto, nas hemonrhagias, produzidas pela inercia uterina, nas insufficiencias das contraccốs durante o parto

Em caixa de 8 e de '3 ampôllas de 1 c. c.

Endovarina - (IS'ucco ovarico) efficacisisimo nos incommodos da menopausa, contra as doenças do sovarios e os: soffrimentos devidos 6 in - sufficiencia, suspensão alterações dos orgams genitaes. Em solução, pastilihas e amipôllas.

Para tomar 3-4 pastilhas, 20-30 gottas, 3-4 vezes por dia, anites das refeições.

Endosplenima - Succo obitido do baço. Accelera e determina os movimentos peristalticos do intestino. Indicado em todos os casos de sim. ples atonia, assim como nos de paralysia intestinal. Indicado na hypertrophia esplenica e na insufficiencia pancreatica. Ampôllas de 10 c. c.,
gottas, pastlias.

Endospermina - (Slucco testicular). Contra a impotencia, neurasthe nia, diminuição da memoria, freuquezas gêraes, „Em solução, pastịlias e ampôllas. Para tomar 3-4 pastilhas; 20-30 gottas 3 vezes por dia antes idas refeições. IAs injeções usam-sie uma cada.dia.

Endotimina - (Thymo de vitello in toto). Reconstituinte na cloroa nemia das críanças, na chlorose da pubescencia, no rachitismo. Pastillhas
e ampólias.

UNICOS CONCCÉSSIONARIOS :。

NO BRASIL :

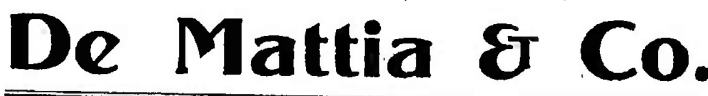

PHARMACIA ITALIANA -::- Rua do Thezouro, 9 H. B. - Para quaesquer iniormações ou explicacớes os snrs. medicos lerão a bondade de dirigtr-se ao DR. EMILIO DE MATTIA - Caixa Postat 384 - SÃO PAULO 
dade sinusal, as raizes das dentes, sendo causa fatal de sinusite, quando estas raizes mergulharem completamente livres no seio, já pela dehiscencia do assoalho alveolar, já pela anterior destruição deste mesmo assoalho.

Apontadas as principaes causas da sinusite, passemos ás referencias sobre o seu diagnostico.

Seja aguda ou chronica, recente ou remota, a sinusite maxillar tem como caracteristico, uma blenorrhéa das fossas nazảes.

$O$ doente queixa-se menos da grande suppuração que 0 faz usar seis e mais lenços por dia, que do máo cheiro, do odôr verdadeiramente nauseante que SO' ELLE SENTE.

Diz mais o doente que pela manhã, ao accordar, este cheiro é mais intenso e nessa occasião sente na bocca e na garganta, um gosto accentuadamente putrido.

A fetidez do pús é tão pronunciada, pela razão de se desenvolver elle em uma cavidade fechada ou quasi fechada como é o seio.

O gosto desagradabilissimo que o doente sente, é devido á passagem do pús do antro para o nazo-pharynge, depois de haver attingido as fossas nazaes, quando o individuo está em decubito.

Faz-se então o exame rhinoscopico: observa-se na fossa nazal incriminada pelo doente, ao nivel do meato medio, uma quantidade variavel de pús.

Algumas vezes nota-se a cavidade em questão, occupada por polypos: outras vezes a mucosa que a recobre, está apenas irritada, irritação que corre por conta do pús que sobre ella passa ou mesmo estaciona.

Quando não constantemente, pelo menos de um modo muito geral, nota-se o corneto inferior hyperemiado.

Póde o doente queixar-se de dôres, que ora são localisadas na região do seio, ora estão generalisadas, abrangendo as zonas de innervação do infra-orbitario e mesmo de outros ramos do trigemio.

Estas sensações dolorosas variam ainda quanto á intensidade; são mais intensas ao dia que durante a noite, o que facilmente se deprehendle da situação do astio nazo-maxillar. 
Situando-se este orificio, muito acima do assoalho sinusal, no começo da suppuração, só quando o individuo está deitado sobre o lado do seio illeso ou quando elle inclina a cabeça para o lado deste seio, é que o escoamento do pús se póde dar.

Fóra destes casos o pús fica retido e esta retensão é que produz a dôr.

Outrosim ha escoamento, o individuo estando sentado ou na estação bipede, quando no antro o pús attinja um nivel superior ao nivel do ostio.

Este escoamento de pús atravez a fossa nazal, constitue um excellente symptoma para o diagnostico da sinusite, como veremos dentro em pouco.

$\mathrm{O}$ pús na fossa nazal póde ser attribuido á mucosa de revestimento desta cavidade; se limparmos o mais rigorosamente possivel a fossa nazal que nos prende a attenção, se retirarmos o pús e os polypos que nella possam existir e depois de meia hora voltarmos á sua observação, veremos que a quantidade de pús ahi accumulada é tal, é relativamente tão grande, que não poderemos deixar de banir a supposição acima referida.

O pús é então de proveniencia extranha á fossa nazal ; por uma observação mais ? attenta veremos que elle ahi chega, na parte mediana do meato medio.

Deste pús no meato medio, ainda não podemos garantir a proveniencia exacta; seu fóco póde ser o seio maxillar como tambem o seio frontal ou as cellulas anteriores do ethmoide.

A suppuração poderá ser dita do seio maxillar, ou quando o pús seja visto irromper do ostio maxillo-nazal ou quando a diaphanoscopia, que passamos a descrever, demonstre estar o seio atacado.

A diaphanoscopia ou transilluminação é um poderoso meio para o diagnostico da sinusite maxillar.

Ao lado da elegancia de que se reveste, possue ella um quasi absoluto valor scientifico.

Porque quasi absoluto? Porque poderão alguns objectar que as paredes osseas sejam naturalmente espessas e o resultado obtido não será uma expressão verda. 
deira: que não haja uma sinusite, mas um outro processo pathologico no seio, impedindo ao observador a percepção da lumin'osidade.

De facto, isto acontecendo, seria errado o diagnostico de sinusite que se fizesse.

Quem praticando a transilluminação diagnosticar uma sinusite e errar por ser outro o mal de que o seio esteja atacado... não será por certo presa de um grande remorso ao abrir o maxillar de u'm seu cliente...

Aproveitar-se-a do erro para combater a molestia que ahi tenha séde...

Quanto á primeira objecçâo, póde-se dizer que a diaphanoscopia não é por ella desvalorisada, visto como são raros, muito raros mesmo, os casos em que as paredes antraes sejam tão espessas que impeçam a travessia da luz. Ainda mais, no caso de duvida, uma puncção trans-meatica esclareceria o caso.

Posto isto, vejamos como se pratica a diaphanoscopia ou transilluminação, cuja descoberta se deve a Heryng.

Quando em uma camara escura, na bocca de um individuo colloca-se uma lampada electrica mandando-se que elle cerre o mais possivel seus labios, as bochechas permitttem ao operador a observação da luz; ao nivel dos bordos orbitarios ou adherentes das palpebras inferiores, apresenta-se, de cada lado, uma nitida faixa luminosa; as pupillas permanecem claras e o paciente fechando as palpebras, tem sensação de luz em ambos os olhos. E' o normal.

Quando haja pús em um dos antros, observa-se que a bochecha correspondente ao antro suppurado não deixa transparecer a luz; neste mesmo lado desapparece a faixa luminosa da orbita, a pupilla fica obscura e o individuo fechando as palpebras só tem sensação luminosa no lado opposto ao da lesão.

Em regra geral, de todos estes signaes, o que melhor revela a existencia de uma sinusite maxillar, é o enfraquecimento ou mesmo o desapparecimento da faixa de luz do bordo adherente da palpebra. 
A differença de transparencia entre as duas boche.. chas póde ser muito pequena, a pupilla do laḍo são póde ser pouca cousa mais clara que sua opposta, mas, as duas iaixas infra-orbitarias differem muito em intensidade quando nisto não contrastam em absoluto.'

Releva notar que a luz empregada deve ser intensificada progressivamente até um gráo não muito elevado pois isto viria perturbar a observação.

Embora colhidas provas positivas na rhinoscopia e na transilluminação, não se deve só por isso garantir ser o caso em presença, uma sinusite maxillar.

Deve-se, antes de ser firmado o diagnostico, confirmal-o.

Esta confirmação nos é dada pela inspecção directa do seio, o que, na realidade, constitue uma operação.

Sendo assim, só é licito o uso deste recurso quando já estiver regularmente bem fundamentada a presumpção de uma sinusite.

Inspecciona-se directamente o seio maxillar, por meio da punç̧ão trans-meatica: como pratical-a?

Por meio de uma agulha ôca deve-se attingir o antro; este é o principio basico da operação.

O ponto por onde deva penetrar a agulha não é todavia o mesmo para todos os operadores.

Queremos dizer com isto que uns o escolhem no meato medio allegando que está neste nivel a região mais delgada da parede nazal lateral; outros preferem o meato inferior, objectando que, ao perfurar o meato medio, um operador embora seja muito habil, não está isento de lesar a parede superior do antro, que é a mesma parede inferior da orbita e offender por esta maneira o globo ocular do operando.

Considerando além disto que a parede nazal lateral, ao nivel do meato inferior, não é de espessura tal a difficultar sobremaneira a operação, parece-nos que a puncção ao nivel deste meato leva vantagens sobre a praticada no meato medio.

E' atravessando-se o meato inferior com uma agulha de Lichtwitz que se deve chegar ao seio maxillar: para is- · 
to o meato foi previamente insensibilisado por uma solução de cocaina a $200 \mid 0$ durante vinte minutos.

Realisada a anesthesia, firma-se a cabeça do doente, colloca-se a ponta da agulha de encontro ao meato inferior, 2 ou ,2,5 centimetros para atraz da abertura da fossa nazal e dahi, dirigindo-a para atraz, para cima e para fóra, fazse com que ella atravesse lentamente a parede ossea e alcance 0 seio.

Verificada tal penetração, porque, com movimentos de bascula é notada a liberdade de sua extremidade anterior no interior da cavidade, adapta-se a ella uma seringa e faz-se a insufflação de ar. Ouve-se o pús gorgolejar dentro do antro e logo apoz assiste-se ao seu escoamento atravez 0 ostio natural.

Algumas vezes, quando o pús sinusal é em pequena quantidade e não póde sahir pela insufflação emprega-se a lavagem exploradora: injecta-se no seio agua esterelisada ou na. falta desta, agua fervida que sahirá pelo ostio nazomaxillar.

Havendo sinusite, havendo suppuração, a agua sahirá do antro, acarretando o pús: dos dois processos, insufflação e lavagem, este é mais expedito.

Ha sinusites em que o pús está caseoso e não póde sahir pelo ostio; outros casos ainda se apresentam, onde o antro é plurilocular.

Nestes dois casos, nem sempre a lavagem e a puncção darão os resultados almejados; quando se não possam empregar os raios $\mathrm{X}$ ou outro meio efficaz, deve-se praticar uma abertura na fosseta canina usando-se da mesma technica que na operação radical, como adeante exporemos.

Comprehende-se que este recurso deve ser o ultimo e o diagnostico de sinusite só deverá ser por elle confirmado, quando já houver uma supposição profunda, uma quasj certeza de se estar deante de um caso de sinusite.

Felizmente estes casos extremos são raros: para a quasi totalidade das sinusites, a lavagem exploradora é uma operação confirmadora sufficiente.

A lavagem deve ser feita lentamente para poupar av 
paciente provaveis dores; o liquido injectado, qualquer que elle seja, deve estar tepido.

Uma vez confirmado o diagnostico, resta o tratamento; varia elle com o gráo em que se encontre a molestia.

Sabe-se que a sinusite ou é aguda ou chronica; parte plahi a duplicidade do tratamento.

Antes de ser este iniciado, compete ao operador definir a sinusite: realmente é difficil a distincção dos dois gráos e ainda aqui a diaphanoscopia parece ser o mais alto recurso, o meio mais seguro. Vejamos como. ticada.

Supponhamos uma sinusite já perfeitamente diagnos-

Se lavarmos o seio affectado, dois casos estarão latentes: transilluminando o seio ou elle readquire a transparencia, apresentando então os signaes que chamamos normaes, a.o descrevermos a technica diaphanoscopica, ou então o seio continua opaco, persistindo todos os signaes que serviram para o diagnostico da sinusite quando se praticou a primeira transilluminação.

Se apoz a lavagem post-diaphanoscopica, o seio readquirir a transparencia, estamos em face de uma sinusite aguda; se nesta occasião o seio permanecer opaco, a sinusite será chronica.

Porque? Sabe-se que nos primeiros tempos da molestia, o seio contem apenas pús e sua mucosa apresenta-se sómente inflammada; uma vez que o processo pathologico evolua livremente, a mucosa sinusal degenera em formações polyposas que mergulham no pús do antro.

Desde que se submetta um seio affectado á uma lavagem mais ou menos rigorosa e elle continua a contrariar a passagem da luz, é claro que seu conteudo não mais se constitue só de pús; ha outros elementos - os polypos. Neste caso, deante da existencia de granulaçồes intra-sinusaes, só devemos concluir por uma sinusite chronica.

Agora, se depois da lavagem o seio readquire a translucidez, parece logico que o seu conteudo era sómente pús, que pelo liquido de lavagem foi acarretado; a sinusite é aguda. 
Consideremos agora o tratamento da sinusite aguda; a cura póde ser expontanea quando a affecção seja devida a um coryza ou á uma rhinite.

Quando seja o caso de ser responsavel por ella, um dente molar, este deve ser extrahido: cumpre ao operador, cuidar do seio depois de haver eliminado o fóco de infecção.

Estes cuidados consistem em lavagens da cavidade, seguindo-se para isto a mesma technica indicada na lavagem exploradora para a confirmação do diagnostico.

A cocainisação do meato inferior cada vez que se pratica a lavagem do seio, apresenta um duplice resultado; anesthesia o local e pela descongestão que provoca nas immediações do ostio, facilita a drenagem.

Uma serie de 12 a 15 lavagens, poderá com relativa facilidade vencer a suppuração, extinguir a sinusite no seu inicio.

Se o pu's que sae do antro, não se mistura ao liquido lavador que o acarreta e não é fetido, póde-se presuppôr que a molestia cederá em breve: se, ao contrario o pús é fetido e francamente miscivel com o liquido que lavou o seio, póde-se esperar por uma lucta demorada entre a pathologia $e$ a therapeutica.

Quando depois de varias lavagens ( 8 a 12 ) o liquido injectado, sae do antro trazendo pús em não pequena quantidade e dotado de fetidez, deve-se aconselhar ao doente a operação radical, porque então o mal não poderá ser considerado agudo e sim, chronico; a lavagem será impotente para fazer cessar a suppuração, porque o antro já não é "um entreposto, um deposito de pús - é uma fabrica".

A operação radical, indicada como indispensavel e insubstitutivel na sinusite chronica, é feita, como dissemos nas nossas primeiras linhas, sob anesthesia local.

O emprego combinado de soluções de cocaina e de novocaina, alliadas á adrenalina, garante uma anesthesia completa e prolongada.

Passemos á descripção da technica a seguir na "radical" da sinusite maxillar chronica, operação que tambem é conhecida sob o nome de Luc-Caldwell. 
Duas são as phases constitutivas desta operação: a da curetagem e a da drenagem.

A primeira das phases, a curetagem, compõe-se, de seis tempos.

$10^{\circ}$ - Na parte superior do vestibulo da bocca, de encontro á parede antero-lateral do maxillar superior, collocar uma tira de algodão embebida em uma solução de chlorhydrato de cocaina a $200 \mid 0$.

IESPERAR QUINZE MINUTOS.

$2 .^{\circ}$ - Dissolver em 5 cc. de sộro physiologico, dez comprimidos de NOVOCAINA-ADRENALINA DE BAUER: não havendo taes comprimidos, preparar a seguinte solução

Sôro physiologico . . . . . . . 100,0

Novocaina . . . . . . ..... ' 2,0

Adrenalina . . . ......... XXX gottas.

Injectar na fossa genal e seus arredores, principalmente nas immediações do nervo infra-orbitario, 2 ou 3 cc. de uma destas soluções.

ESPERAR CINCO MTNUTOS.

$3 .^{\circ}$ - Seccionar a mucosa gingival em uma extensão ,approximada de 3 centimetros, entre o rebordo inferior da gengiva e o angulo gingivo-jugal; a secçã̃o deve ser feita calculadamente, afim de que não sejam lesados o canal de Stenon e o nervo infra-orbitario. Feita a secção, descolar as partes molles e o periosteo correspondentes á esta região. Remover a parte inferior da face anterior do antro.

$4 .^{\circ}$ - Remover o mais possivel as granulações (polypos) intra-sinusaes, remoção que deve de preferencia, ser feita com a pinça de Brunning.

$5 .^{\circ}$ - Introduzir no antro uma gaze embebida em uma solução a 5 o| 0 0 de chlorhydrato de cocaina á qual se tem accrescentado gottas de adrenalina; introduzir no meato inferior um pequeno tampão de algodão impregnado desta mesma solução.

ESPERAR CINCO MINUTOS, o paciente inclinando a cabeça para a frente e para baixo. 
6. - Curetar meticulosa e cuidadosamente o antro, tendo redobrada attenção ao, curetar as paredes superior e posterior da cavidade para evitar que por lesões nellas, sobrevenham respectivamente ou um tumor retro-bulbar ou uma secção da arteria maxillar interna.

A 2.a phase da operação é tomada por dois tempos.

No primeiro, pratica-se uma contra-abertura na face nazal lateral, estabelecendo-se assim, a continuidade do antro com a cavidade nazal.

No segundo tempo intròduz-se no antro uma gaze iodoformaida cuja extremidade anterior, passando pelo orificio ultimamente praticadio, fica na fossa nazal.

Occupado o antro pela gaze, suturam-se as partes molles que foram descoladas, para evitar que ao se refundirem penetrem na cavidade sinusal, difficultando quando não impedindo a reconstituição do tecido osseo.

Vinte e quatro ou quarenta e oito horas apoz a operação, retira-se a gaze iodoformada, puxando-se a extremidade que ficou na cavidade nazal.

Para maior facilidade (isto fica para os principiantes) á medida que ella fôr puxada, deve ser torcida, para que suas malhas se não prendam ás asperezas dos rebordos da abertura nazo-maxillar.

Retirada a gaze, nesse dia ou no dia seguinte e assim duas ou tres vezes por semana, faz-se uma lavagem no antro, passando-se a sonda pelo orificio que deu antes passagem á gaze.

Fistas lavagens serão feitas até que o liquido injectadc, ao sahir do seio não apresente vestigio algum de pús.

Nos dois primeiros dias post-operatorios, é de bom aviso o operado tomar alimentos que não dependam de muita mastigação.

Por este mesmo tempo póde elle recomeçar o seu trabalho e no fim de 20 ou 30 dias seu estado de saude está completamente restabelecido quasi sempre sem ulteriore.s complicações. 